\title{
Assessment of Depression Among Older Adults Staying in Old Home Care in Klang, Malaysia
}

\author{
Muhammad Qamar*, Nurul Zahirah, Sohail Ahmad \\ Department of Clinical Pharmacy, Faculty of Pharmacy, MAHSA University, Bandar Saujana Putra, 42610 Jenjarom, \\ Kuala Langat, Selangor, Malaysia
}

\begin{abstract}
Mental disorders such as depression are widespread, often underdiagnosed, and usually inappropriately treated. The early recognition of factors that may promote depression with the help of depression screening aid can help to plan better care for the patient. Therefore, this study aimed to determine the depression prevalence among the older adults staying in old home care, to explore any association and differences of depression across various socio-demographic variables, and to study the predictors of depression among study subjects. A cross-sectional study was conducted with a convenience sample of 141 elderly by using the validated tool. The study instrument was divided into two sections: Section I (Socio-demographic data); Section II (M-Geriatric Depression Scale-14). The results showed $44.7 \%$ were in the age group of $65-75$ years, the majority were Chinese $(42.6 \%)$, and male $(57.4 \%)$. Among the subjects, $43.3 \%$ had hypertension, followed by $39 \%$ of diabetes, and $8.5 \%$ were with heart disease, while more than $90 \%$ reported not known history of depression. The study revealed that more than $50 \%$ of the respondents had depression. Statistically, a significant difference was observed between the depression prevalence with marital status $(\mathrm{p}=0.021)$ and a history of heart disease $(\mathrm{p}=0.002)$. On multivariate analysis, heart disease was found to be statistically significant. Depression was prevailing among the older community those who were staying in old home care. Daily evaluation should be done for the older population staying in old home care to attenuate the prevalence of depression. Family and social support were vital to highlight the issue of depression among older adults.
\end{abstract}

Keywords: depression, older adults, old home care, Klang, Malaysia

*corresponding author

Email:mqamar18@gmail.com

\section{INTRODUCTION}

Worldwide countries around the world are experiencing an increase in the older population. Globally, it is estimated that the populace of the elderly would increase by $21 \%$ in the next 5 decades and it is expected that the population of geriatric will increase to fourfold by the year 2050. Most probably, it would be almost 2 billion in the developing nations (Venne, 2005). The total population of Malaysia is 25 million and is consists of various ethnic groups, among which major are Malays followed by Chinese, Indian, and foreigner immigrants laborers (Mat, 2003). From the past 20 years, there has been a positive change in statistics of the Malaysian population. It is expected that in the year 2020, more than $10 \%$ of Malaysians will be at the age of 60 years and more. This is due to better health care, longer life expectancy, and low death rate as well as a decline in fertility (Department of Statistic, 1998).

However, mental health is important to the elderly population, among which those who need it only a small fraction of them receive mental health service (Andrews et al., 1999). By one estimation, only about $10 \%$ of geriatric who are in need of psychiatric treatment ever receive this service (Friedhoff, 1991).

Depression is a mood disorder and also a state of feeling unhappy, miserable, and loss of self-confidence, which eventually will cause a loss of interest. Depression is usually related to morbidity and mortality, thus making it more significant and common in the geriatric population (Prashanth et al., 2015). Psychiatric disorders such as depression are especially prevalent among geriatric with a prevalence of approximately $10-15 \%$ worldwide (Choulagai et al., 2013). Consequences of depression include poor quality of life, social deprivation, loneliness, reduction of quality in activities of daily living, cognitive diminish, suicide as well as increased mortality (Steffens et al., 2000). Every year, there was over 800.000 individuals die due to suicide according to a report of the World Health Organization (WHO, 2008).

As people are aging, depression is not a natural part of it (Yesavage et al., 1982). Depression is usually can be reversed with quick recognition and proper treatment (Brown et al., 2003). Very frequently, the geriatric has difficulty in recognizing depression and/or reporting it to 
their care providers. This is the reason why only a few of the depression cases are detected or treated (Cole et al., 1999). Further adding to this problem, if depression was left untreated, it might lead to the onset of functional, cognitive, physical and social disabilities as well as a reduction in quality of life, lengthen the recovery from medical disease and surgery, higher health care utilization and suicide (Yesavage et al., 1982).

Depression is accounting for large morbidity and mortality within the elderly section of the society (Blazer, 2003). Based on the report of the World Health Organization (WHO), the size of the elderly section of the society has shown a fast and significant growth. Therefore, it is important to make the health and fitness issue of this population in our health care system (WHO, 2008).

In order to determine the nature and magnitude of depression, the screening and assessment of depression among the geriatric staying in nursing home care are necessary (Lyness et al., 1997). Structured Clinical Interview for DSM-IV (SCID) is one of the diagnostic instruments, but this instrument is not regularly used in the home care setting (Spitzer et al., 1992). There is no specific information regarding the validity of the standardized screening process that was related to diagnostic criteria in those populations, although screening for depression is the key element of a complete assessment in an old care center (Marc et al., 2008).

The Geriatric Depression Scale (GDS) is one of the most widely used tool for assessing the depression among the geriatric in a primary care setting. This tool is freely available with no copywrite issue. It is available in two version (GDS-30 and GDS15) using a different cut-off values and across different setting (Mitchell et al., 2010; Pocklington et al., 2016; Watson \& Pignone, 2003). It is available in many languages including English, Spanish, Malay, Dutch, Korean, Farsi and Tai. However, the original GDS has 30-items (GDS-30), the shorter version of GDS with 15-items (GDS-15) scale was validated against the longer GDS-30 scale, and the GDS15 is recommended to be used in primary care settings (Mitchell et al., 2010; Yesavage \& Sheikh, 1986). In 2016, meta analytic review was conducted to examine the diagnostic accuracy of the shorter version (15 items or less) of the geriatric depression scale against the gold standard tools (DSM-IV and ICD-10) to diagnose the major depressive disorders (Pocklington et al., 2016).

The Geriatric Depression Scale-15 (GDS-15) was a suitable tool for assessing and screening of depression in the general population across different age, gender, ethnicity, and chronic illness status (De Craen et al., 2003). Early detection and effective interventions are crucial for improving the functioning of the elderly and hence the quality of life. It has been described previously, somewhere else, about the validation, factor structure, and also the overall development of GDS-15. GDS-15 has been evaluated in a variety of populations including inpatients, outpatients, primary care, and nursing homes. On the other hand, the short form is more suitable as well as practical to be used among the elderly, whereas its administration to home care patients who was burdened with lack of medical and functional status has not been reported.

The objective of the present study was to determine the prevalence of depression among older subjects living in geriatric home care in the region of Klang, Malaysia, to identify the differences and association between the depression and sociodemographic characteristic of respondents and predictors of depression among elderly people living in geriatric home care.

\section{METHOD}

\section{Research Design and Subjects}

A cross-sectional descriptive study was conducted in the city of Klang by using a validated questionnaire. The recommended sample size with 5\% margin of error, $95 \%$ confidence interval with $50 \%$ response distribution, was 141 respondents as calculated by the online Raosoft calculator. Before enrolling, a consent form was signed from respondents. This study recruited the elderly people age $\geq 65$ years old who were living in geriatric home care.

\section{Data Collection}

Elderly individuals living in old folks home were approached after taking approval from person In-charges of folk's homes and written consent from respondents. All of them gave consent to participate in the study. The study questionnaire was distributed at 5 different old age homes in Klang. Respondents were requested to respond to the questionnaire on the spot, and it was collected after completion. The subjects were enrolled by convenience sampling.

\section{Inclusion and Exclusion Criteria}

Elderly subjects were enrolled with inclusion criteria of age $\geq 65$ years and respondents staying in the old folk home for $\geq 6$ months (permanent or temporary resident). Participants with serious morbidities such as psychiatric illness despite depression, critically ill elderly, advanced heart disease or chronic renal disease, cancer, and elderly with severe hearing or speech impairment, making the elderly unable to comprehend the questions were excluded from this study. 


\section{Malay Geriatric Depression Scale-14 (M-GDS-14)} GDS-15 was translated to Malay language and validated. The Malay version of GDS is a reliable and valid tool as like with original 30 or 15 items version (Ewe \& Che Ismail, 2004). Item-9 of the GDS-15 was omitted due to its non-discriminatory value in clinical diagnosis of depression and poorly correlated with total item score, thus making it a 14-items scale with Cronbach's alpha score of 0.84 , with test-retest validity of 0.84 (Ewe \& Che Ismail, 2004). Malay version of geriatric depression scale (M-GDS-14) is based on the Geriatric Depression Scale (GDS-15) as recommended by Royal College of Physicians, British Geriatric Society and The Royal College of General Practitioners that GDS-15 is a suitable tool to screen for depression in the older adults. In the current study, M-GDS-14 scale was used to assess and determine the prevalence of the depression among elderly respondents.

The M-GDS-14 consisted of 14 "Yes" and "No" questions. The score was obtained by summing up the responses of positive and negative answers. The first part of the questionnaire consisted of information regarding the socio-demographic variables and the second part of the questionnaire includes Malay Geriatric Depression Scale (M-GDS-14) for depression level measurement. The study subjects were asked to respond to 14 items by responding 'yes' or 'no' in reference to how they felt on the day the questionnaire was administered. A score of more than 5 points in GDS-14 indicated depression and was categorized with the cut of the value of $0-4$ are considered normal; 5-8 indicate mild depression; 9-11 indicate moderate depression, and 12-15 indicate severe depression. Moreover, the score between 5 to 9 indicated as suggestive depression, while score $\geq 10$ indicated as depression. However, respondents with a score $>5$ points were advisable to get a follow-up comprehensive assessment. On the basis of formal interview diagnostic criteria evaluation, the GDS was found to have sensitivity and specificity of $92 \%$ and $89 \%$, respectively (Yesavage \& Sheikh, 1986).

\section{Ethical Consideration}

The study was approved by the ethics board of the Research Management Centre (RMC) of MAHSA University. Individual participation in this study was voluntary. Oral, as well as written consent, was taken from each subject. Confidentiality and anonymity of all participants were maintained as no names were mentioned in the questionnaires.

\section{Statistical Analysis}

The extracted data from completed questionnaires were analyzed using Statistical Package for the Social Sciences ${ }^{\circledR}$. Descriptive and inferential statistics were used to express the data. The geriatric depression scale consisted of "Yes" and "No" category and the depression score ranged from $0-15$ and the cut-off level was determined as $<5$ points which indicated no depression category, 5-9 points which fell under suggestive of depression or mild depression and $\geq 10$ points which fell under indicative of depression. Independent t-test and ANOVA test were used to find the differences in depression scores across various sociodemographic categories and medical illnesses. Pearson's Chi-Squared test was used to find the association between socio-demographic data and medical illnesses with the depression score category. Logistic regression was used to find the predictors of depression. The level of statistical significance was set at $\mathrm{p}<0.05$.

\section{RESULTS}

\section{Socio-Demographic Data of the Respondents}

Out of 150,141 respondents aged $\geq 65$ years old gave their consent to participate and return the questionnaire to the principal research. Therefore, the response rate of the study was $94 \%(141 / 150)$ that surpassed the good index of response rate. It can be observed that most respondents who participated in this study were male $(57.4 \%)$ with inclusive of major ethnicity Chinese (42.6\%), followed by Malay $(32.6 \%)$, and Indian $(24.8 \%)$. The majority of respondents who enrolled in this study were within the age range of $65-70(44.7 \%)$. In this study, the marital status of widow/widower was found to be the highest, with $41.1 \%$ (Table 1 ).

Table 1: Socio-demographic data of the respondents $(n=141)$

\begin{tabular}{lll}
\hline Sociodemographic & Category & N (\%) \\
\hline \multirow{3}{*}{ Gender } & Male & $81(57.4)$ \\
& Female & $60(42.6)$ \\
Age & $65-70$ & $63(44.7)$ \\
& $71-75$ & $22(15.6)$ \\
& $\geq 76$ & $56(39.7)$ \\
Ethnicity & Chinese & $60(42.6)$ \\
& Malay & $46(32.6)$ \\
& Indian & $35(24.8)$ \\
& & \\
Marital Status & Married & $17(12.1)$ \\
& Single & $43(30.5)$ \\
& Widow/widowed & $58(41.1)$ \\
& Divorced & $23(16.3)$ \\
\hline
\end{tabular}

\section{Medical Illnesses of the Respondents}

Regarding medical illness, $43.3 \%$ of the respondents were diagnosed with hypertension, followed by diabetes mellitus (39\%) and hypercholesterolemia (22.7\%), while $99.3 \%$ of subjects reported with no history of depression (Table 2). 
Table 2: Medical illness of the geriatric respondents in geriatric home care in Klang $(n=141)$

\begin{tabular}{lll}
\hline Medical Illness & Status & N (\%)* \\
\hline Diabetes Mellitus & Yes & $55(39)$ \\
Hypertension & Yes & $61(43.3)$ \\
Hypercholesterolemia & Yes & $32(22.7)$ \\
Heart Disease & Yes & $12(8.5)$ \\
Osteoarthritis & Yes & $14(9.9)$ \\
Asthma & Yes & $10(7.1)$ \\
COPD & Yes & $7(5)$ \\
Cataracts & Yes & $2(1.4)$ \\
Depression & Yes & $1(0.7)$ \\
\hline
\end{tabular}

$* \%>100$ (Multi response)

\section{Scores of Geriatric Depression Scale}

Out of 141 geriatric respondents, 34 subjects had a score $\geq 10(24.1 \%$ [34/141]), which was an indication of depression, whereas 40 respondents attained the score range between 5-9 (28.4\% [40/141]) which was suggestive of depression (Table 3). Those who score more than 5 points were advised to have a follow-up comprehensive assessment with psychiatrists for proper diagnosis.

Table 3: Scores of Geriatric Depression Scale (GDS)

\begin{tabular}{lll}
\hline GDS & (Score) & N (\%) \\
\hline No depression & $<5$ & $67(47.5)$ \\
Suggestive of depression & $5-9$ & $40(28.4)$ \\
Indicative of depression & $\geq 10$ & $34(24.1)$ \\
\hline
\end{tabular}

Differences, Association, and Regression between Socio-Demographic Data and Depression

Based on the findings of inferential statistics (Table 4), significant differences were observed between geriatric depression scores across marital status $(\mathrm{p}=0.021)$ and a history of heart disease $(\mathrm{p}=0.002)$. But no statistically significant association was observed between the depression categories across the socio-demographics of the respondents (Table 5). On multivariate analysis, history of heart disease was found to be primary predictors for depression (Table 6).

\section{DISCUSSION}

Mental disorder such as depression was frequently reversible with immediately and desirable treatment. If it was left without medical care, it might also result in the onset of cognitive, physical, and social impairment and delay the recovery from medical disease and surgery. Consequently, increased health care services and suicide (Rashid et al., 2011).
According to the World Health Organization (WHO) predicted that depression would be one of the major burdens of illness in most of the developing countries (Murray, 1996). Among geriatrics, one in six patients affected with depression and had been treated in general medical practice and indeed higher percent in hospitals and nursing homes (Reynolds \& Kupfer, 1999)

The present study reported that the overall prevalence of depression in the enrolled respondents from the nursing home was $52.5 \%$. It was one of the most common psychiatric disorders in the elderly population, especially among those who are living in nursing home care ( $\mathrm{Li}$ et al., 2015). The percentage of those residents who were affected by the condition in the forms of depressive symptoms of depression, major and minor depression was approximately $15 \%$ to $52 \%$ (Ames, 1993).

Prevalence of depression among the geriatric people living in community was $15.6 \%$ while those staying in old age home was $27.7 \%$ (Abhishek et al., 2015) whereas in another study by Mann et al. (2000) in the United Kingdom reported that elderly residing in old age home found to have $40 \%$ prevalence (Mann et al., 2000). It had been found that the depression prevalence varied from one study to another. These differences were most probably due to diagnostic criteria used to assessed and measure depression, differ in culture, and diversity in the population (Evans \& Mottram, 2000). There was evidence indicating higher rates of depression in old age home/nursing home compared to the community (Rovner et al., 1986; Grayson et al., 1995).

Marital status had shown a significant difference $(\mathrm{p}=0.021)$ with a mean depression score. The finding from the current study revealed that geriatric who are divorced had a higher depression score as compared to single and married. It had shown that marriage was one of the protective factors against depression in the elderly population (Chen, 2008). The finding was consistent with the previously reported studies conducted in private clinics in Malaysia (Sidik et al., 2003; Imran et al., 2009). It was assumed that people who were married were prone to have less stressful experiences in their whole married life and thus have less chance of being depressed. On the other hand, another reason for being depressed, single elderly might feel isolated because of the lack of togetherness. Being alone was one of the risk factors for depression. The elderly community who were living alone either in a community or in nursing care were vulnerable to loneliness (Chen, 2008; Savikko et al., 2005).

Moreover, depression was also prevalent in a patient with heart failure (HF). Approximately one in five HF patients present with depression, with about $48 \%$ of 
Table 4: Differences between sociodemographic data with depression score

\begin{tabular}{|c|c|c|c|c|}
\hline Variables & n & Mean $( \pm$ SD) & $\begin{array}{l}\text { df }(\text { t-stat })^{1} / \\
\text { df }(\text { f-stat })^{2}\end{array}$ & p-value \\
\hline \multicolumn{5}{|l|}{ Gender } \\
\hline Male & 81 & $5.72(4.16)$ & \multirow[t]{2}{*}{$139(-1.109)^{1}$} & \multirow[t]{2}{*}{0.269} \\
\hline Female & 60 & $6.48(3.93)$ & & \\
\hline \multicolumn{5}{|l|}{ Age } \\
\hline $65-70$ & 63 & $5.63(3.89)$ & \multirow[t]{3}{*}{$2(1.35)^{2}$} & \multirow[t]{3}{*}{0.260} \\
\hline $71-75$ & 22 & $5.45(3.82)$ & & \\
\hline$\geq 76$ & 56 & $6.73(4.31)$ & & \\
\hline \multicolumn{5}{|l|}{ Ethnicity } \\
\hline Malay & 46 & $5.76(3.61)$ & \multirow{3}{*}{$2(0.591)^{2}$} & \multirow[t]{3}{*}{0.555} \\
\hline Chinese & 60 & $5.88(4.10)$ & & \\
\hline Indian & 35 & $6.69(4.58)$ & & \\
\hline \multicolumn{5}{|l|}{ Marital Status } \\
\hline Married & 17 & $6.06(4.05)$ & \multirow[t]{4}{*}{$3(3.357)^{2}$} & \multirow[t]{4}{*}{$0.021 *$} \\
\hline Single & 43 & $5.19(3.88)$ & & \\
\hline Window & 58 & $5.76(3.70)$ & & \\
\hline Divorced & 23 & $8.35(4.65)$ & & \\
\hline \multicolumn{5}{|l|}{ Medical Illness } \\
\hline Diabetes & & & \multirow{3}{*}{$139(-0.778)^{1}$} & \multirow{3}{*}{0.438} \\
\hline Yes & 55 & $5.71(4.08)$ & & \\
\hline No & 86 & $6.26(4.06)$ & & \\
\hline \multicolumn{5}{|l|}{ Hypertension } \\
\hline Yes & 61 & $5.38(3.62)$ & \multirow[t]{2}{*}{$139(-1.709)^{1}$} & \multirow[t]{2}{*}{0.090} \\
\hline No & 80 & $6.55(4.32)$ & & \\
\hline \multicolumn{5}{|l|}{ Heart Disease } \\
\hline Yes & 12 & 9.42 (4.99) & \multirow[t]{2}{*}{$139(3.097)^{1}$} & \multirow[t]{2}{*}{$0.002 *$} \\
\hline No & 129 & $5.73(3.84)$ & & \\
\hline \multicolumn{5}{|l|}{ Osteoarthritis } \\
\hline Yes & 14 & $6.43(4.83)$ & \multirow[t]{2}{*}{$139(0.373)^{1}$} & \multirow[t]{2}{*}{0.710} \\
\hline No & 127 & $6.00(3.99)$ & & \\
\hline \multicolumn{5}{|l|}{ Asthma } \\
\hline Yes & 10 & $8.10(4.22)$ & \multirow[t]{2}{*}{$139(1.671)^{1}$} & \multirow[t]{2}{*}{0.097} \\
\hline No & 131 & $5.89(4.02)$ & & \\
\hline \multicolumn{5}{|l|}{ COPD } \\
\hline Yes & 7 & $7.71(4.46)$ & \multirow[t]{2}{*}{$139(1.117)^{1}$} & 0.266 \\
\hline No & 134 & $5.96(4.04)$ & & \\
\hline
\end{tabular}

${ }^{1}$ Independent t-test, ${ }^{2}$ ANOVA

these individuals were having significant depression (Mbakwen, 2016). The finding from the current study also showed that elderly with heart failure had a higher depression score than with non-heart failure patient and was significantly associated $(p=0.002)$ with depression.

Based on community studies, a statistic from systematic review and meta-analysis found that on an average prevalence of clinically acceptable depressive syndrome of $13.5 \%$ among the elderly aged 55 or older. Among which $9.8 \%$ was grouped as minor depression and $1.8 \%$ as major depression (Cole \& Dendukuri, 2003).
Besides, studies conducted by Norsiah and Sherina on depression among geriatric in primary health care centers indicated a higher prevalence of depression of $14 \%$ and 18\%, respectively (Norsiah, 1999; Sherina, 2002). The higher depression prevalent in these studies was certainly due to the higher underlying morbidity of elderly attending primary health care centers, while a high percentage of prevalence of depression in our study was most likely due to the loneliness (divorced) staying in geriatric home care. 
Table 5: Association between depression score category across the socio-demographic (n=141)

\begin{tabular}{|c|c|c|c|c|}
\hline \multirow[b]{2}{*}{ Variables } & \multicolumn{3}{|c|}{ Score n $(\%)$} & \multirow[t]{2}{*}{ p-value * } \\
\hline & $\begin{array}{c}\text { Normal } \\
<\mathbf{5}\end{array}$ & $\begin{array}{c}\text { Suggestive } \\
5-9\end{array}$ & $\begin{array}{c}\text { Indicative } \\
\geq 10\end{array}$ & \\
\hline \multicolumn{5}{|l|}{ Gender } \\
\hline Male & $42(62.7)$ & $18(45)$ & $21(61.8)$ & 0.170 \\
\hline Female & $25(37.3)$ & $22(55)$ & $13(38.2)$ & \\
\hline \multicolumn{5}{|l|}{ Age } \\
\hline $65-70$ & $33(49.3)$ & $17(42.5)$ & $13(38.2)$ & 0.299 \\
\hline $71-75$ & $10(14.9)$ & $9(22.5)$ & $3(8.8)$ & \\
\hline$\geq 76$ & $24(35.8)$ & $14(35)$ & $18(52.9)$ & \\
\hline \multicolumn{5}{|l|}{ Ethnicity } \\
\hline Malay & $24(35.8)$ & $13(32.5)$ & $9(26.5)$ & 0.290 \\
\hline Chinese & $26(38.8)$ & $21(52.5)$ & $13(38.2)$ & \\
\hline Indian & $17(25.4)$ & $6(15)$ & $12(35.3)$ & \\
\hline \multicolumn{5}{|l|}{ Marital Status } \\
\hline Married & $8(11.9)$ & $5(12.5)$ & $4(11.8)$ & 0.178 \\
\hline Single & $25(37.3)$ & $9(22.5)$ & $9(26.5)$ & \\
\hline Widow/Widower & $2841.8)$ & $19(47.5)$ & $1132.4)$ & \\
\hline Divorced & $6(9)$ & $7(17.5)$ & $10(29.4)$ & \\
\hline
\end{tabular}

* Chi-square test

Table 6: Multivariate analysis of selected characteristic of having depression among geriatrics

\begin{tabular}{|c|c|c|}
\hline Variables & Adjusted odd ratio $(95 \% \mathrm{CI})$ & p-value \\
\hline $\begin{array}{l}\text { Gender } \\
\text { Female } \\
\text { Male }\end{array}$ & $\begin{array}{l}\text { Reference } \\
1.876(0.91-3.86)\end{array}$ & 0.087 \\
\hline $\begin{array}{l}>75 \\
65-75\end{array}$ & $\begin{array}{l}\text { Reference } \\
0.730(0.34-1.54)\end{array}$ & 0.411 \\
\hline $\begin{array}{c}\text { Marital Status } \\
\text { Married } \\
\text { Unmarried* }\end{array}$ & $\begin{array}{l}\text { Reference } \\
0.941(0.31-2.84)\end{array}$ & 0.913 \\
\hline $\begin{array}{c}\text { Diabetes Mellitus } \\
\text { No } \\
\text { Yes }\end{array}$ & $\begin{array}{l}\text { Reference } \\
1.267(0.57-2.77)\end{array}$ & 0.554 \\
\hline $\begin{array}{c}\text { Hypertension } \\
\text { No } \\
\text { Yes }\end{array}$ & $\begin{array}{l}\text { Reference } \\
1.156(0.52-2.56)\end{array}$ & 0.722 \\
\hline $\begin{array}{c}\text { Hypercholesterolemia } \\
\text { No } \\
\text { Yes }\end{array}$ & $\begin{array}{l}\text { Reference } \\
0.652(0.25-1.65)\end{array}$ & 0.367 \\
\hline $\begin{array}{c}\text { Heart Disease } \\
\text { No } \\
\text { Yes }\end{array}$ & $\begin{array}{l}\text { Reference } \\
5.553(1.09-28.11)\end{array}$ & 0.038 \\
\hline $\begin{array}{c}\text { Osteoporosis } \\
\text { No } \\
\text { Yes }\end{array}$ & $\begin{array}{l}\text { Reference } \\
1.227(0.37-4.02)\end{array}$ & 0.736 \\
\hline $\begin{array}{l}\text { Asthma } \\
\text { No } \\
\text { Yes }\end{array}$ & $\begin{array}{l}\text { Reference } \\
2.33(0.53-10.2)\end{array}$ & 0.261 \\
\hline $\begin{array}{l}\text { COPD } \\
\text { No } \\
\text { Yes }\end{array}$ & $\begin{array}{l}\text { Reference } \\
2.97(0.50-17.46)\end{array}$ & 2.97 \\
\hline
\end{tabular}




\section{CONCLUSION}

The depression prevailing among geriatric staying in geriatric home care was high in Malaysia. Heart failure and divorced were significantly associated with depression. These factors were modifiable.

Nursing home care providers should come up with a proper assessment program on screening of depression among the elderly in their center. It was advisable to identify and assessed the risk factors of depression and then treated accordingly to facilitate depression among the elderly.

In general, the prevalence of depression among elderly living in the old folk home needed to be alleviated and should be addressed in order to increase the awareness of mental health and to make ensure that they have a happier and healthier life at a home care center.

The obvious limitation of the current study was a crosssectional study design so that results could not be generalized for all geriatric people staying in nursing home care in Malaysia.

Further research was also required to recognize the risk factors of elevation of depression among the elderly. This might help in improving their quality of life in the future as well as contribute to the emancipation of the elderly. The majority of depressed participants expressed their satisfaction in living in geriatric home care. However, there was a need for a bigger study to be conducted to confirm these outcomes as this study may not have sufficient strength to identify the depression caused by these demographic variables in geriatric home care in Malaysia.

\section{ACKNOWLEDGMENTS}

The authors wish to thank the elderly for their full cooperation during data collection and authors also grateful to all the centers permitting us to conduct the study in their center.

\section{REFERENCES}

Abhishek, G., Uday, M., Singh Shivendra, K., Manish, M. K., Chandra, T. S., \& Kumar, S. V. (2015). Screen depression among elderly in a city Asia. Journal of Clinical and Diagnostic Research, 9(9), 3-7.

Ames, D. (1993). Depressive disorders among elderly people in long-term institutional care. Australian and New Zealand Journal of Psychiatry, 27(3), 379-391.
Andrews, G., Hall, W., \& Teesson, M. (1999). Henderson S1. The mental health of Australians. Canberra, ACT: Commonwealth of Australia Department of Health and Aged Care.

Blazer, D. G. (2003). Depression in late life: review and commentary. The Journals of Gerontology Series A: Biological Sciences and Medical Sciences, 58(3), M249-M265.

Brown, E. L., McAvay, G., Raue, P. J., Moses, S., \& Bruce, M. L. (2003). Recognition of depression among elderly recipients of home care services. Psychiatric Services, 54(2), 208-213.

Chen, R., Hu, Z., Wei, L., Qin, X., McCracken, C., \& Copeland, J. R. (2008). Severity of depression and risk for subsequent dementia: cohort studies in China and the UK. The British Journal of Psychiatry, 193(5), 373-377.

Choulagai, P. S., Sharma, C. K., \& Choulagai, B. P. (2013). Prevalence and associated factors of depression among elderly population living in geriatric homes in Kathmandu Valley. Journal of Institute of Medicine, 35(1), 39-44.

Cole, M. G., Bellavance, F., \& Mansour, A. (1999). Prognosis of depression in elderly community and primary care populations: a systematic review and metaanalysis. American Journal of Psychiatry, 156(8), 11821189.

Cole, M. G., \& Dendukuri, N. (2003). Risk factors for depression among elderly community subjects: a systematic review and meta-analysis. American journal of psychiatry, 160(6), 1147-1156.

de Craen, A. J., Heeren, T. J., \& Gussekloo, J. (2003). Accuracy of the 15-item geriatric depression scale (GDS-15) in a community sample of the oldest old. International journal of geriatric psychiatry, 18(1), 63-66.

Department of Statistics. Malaysia. (1998) Senior citizens and population. Ageing in Malaysia. Population Census Monograph Series no. 4. Kuala Lumpur. National Printing Department.

Evans, M., \& Mottram, P. (2000). Diagnosis of depression in elderly patients. Advances in psychiatric treatment, 6(1), 49-56.

Ewe, E. T., \& Che Ismail, H. (2004). Validation of Malay version of Geriatric Depression Scale among elderly inpatients. Age, 17, 65-4. URL:www.priory.com/psych/ MalayGDS.htm 
Friedhoff, A. J. (1991). Consensus development statement: Diagnosis and treatment of depression in late life. In Diagnosis and treatment of depression in late life: Results of the NIH consensus development conference (pp. 493-511).

Grayson, P., Lubin, B., \& Van Whitlock, R. (1995). Comparison of depression in the community-dwelling and assisted-living elderly. Journal of Clinical Psychology, 51(1), 18-21. http://www.Mentalhealth. Com/Book/Pus-Dpo1htm [access June 2008]

Imran, A., Azidah, A. K., Asrenee, A. R., \& Rosediani, M. (2009). Prevalence of depression and its associated factors among elderly patients in outpatient clinic of Universiti Sains Malaysia Hospital. The Medical Journal of Malaysia, 64(2), 134-139.

Li, Z., Jeon, Y. H., Low, L. F., Chenoweth, L., O'Connor, D. W., Beattie, E., \& Brodaty, H. (2015). Validity of the geriatric depression scale and the collateral source version of the geriatric depression scale in nursing homes. International psychogeriatrics, 27(9), 14951504.

Lyness, J. M., Noel, T. K., Cox, C., King, D. A., Conwell, Y., \& Caine, E. D. (1997). Screening for depression in elderly primary care patients: A comparison of the Center for Epidemiologic Studies-Depression Scale and the Geriatric Depression Scale. Archives of internal medicine, 157(4), 449-454.

Mann, A. H., Schneider, J., Mozley, C. G., Levin, E., Blizard, R., Netten, A., ... \& Todd, C. (2000). Depression and the response of residential homes to physical health needs. International Journal of Geriatric Psychiatry, 15(12), 1105-1112.

Marc, L. G., Raue, P. J., \& Bruce, M. L. (2008). Screening performance of the 15-item geriatric depression scale in a diverse elderly home care population. The American Journal of Geriatric Psychiatry, 16(11), 914-921.

Mat, R. (2003). 2003. Socio-economic characteristics of elderly in Malaysia. In 21st Population Census Conference, Kyoto, 2003 (pp. 19-21).

Mbakwem, A., Aina, F., \& Amadi, C. (2016). Expert opinion-depression in patients with heart failure: is enough being done?. Cardiac failure review, 2(2), 110.

Mitchell, A. J., Bird, V., Rizzo, M., \& Meader, N. (2010). Diagnostic validity and added value of the Geriatric Depression Scale for depression in primary care: a metaanalysis of GDS30 and GDS15. Journal of affective disorders, 125(1-3), 10-17.
Sidik, M.S., Zulkefli, N. A. M, \& Shah, S. A. (2003). Factors associated with depression among elderly patients in a primary health care clinic in Malaysia. Asia Pacific Family Medicine, 2(3), 148-152.

Murray, C. J., Lopez, A. D., \& World Health Organization. (1996). The global burden of disease: a comprehensive assessment of mortality and disability from diseases, injuries, and risk factors in 1990 and projected to 2020: summary. World Health Organization.

Norsiah, M. N. (1999). Prevalence of depression among the elderly attending Klinik Kesihatan Pokok Sena and who do they go for help. MMed Thesis. Universiti Kebangsaan Malaysia.

Pocklington, C., Gilbody, S., Manea, L., \& McMillan, D. (2016). The diagnostic accuracy of brief versions of the Geriatric Depression Scale: a systematic review and meta-analysis. International Journal of Geriatric Psychiatry, 31(8), 837-857.

Prashanth, A. K., Rakesh, M. P. K., Praveena, V., Preethi, A., Prithvi, S., Priyadharshini, R., \& Suvetha, K. (2015). A cross-sectional study analysing the level of depression and its causative factors among patients visiting a multispecialty hospital. Advanced medical sciences: An international journal, 4(2), 1-6.

Rashid, A., Manan, A., \& Rohana, S. (2011). Depression among the elderly Malays living in rural Malaysia. The Internet Journal of Public Health, 1(2), 128-136.

Reynolds III, C. F., \& Kupfer, D. J. (1999). Depression and aging: a look to the future. Psychiatric Services, 50(9), 1167-1172.

Rovner, B. W., Kafonek, S., Filipp, L., Lucas, M. J., \& Folstein, M. F. (1986). Prevalence of mental illness in a community nursing home. The American journal of psychiatry, 143(11), 1446-1449.

Savikko, N., Routasalo, P., Tilvis, R. S., Strandberg, T. E., \& Pitkälä, K. H. (2005). Predictors and subjective causes of loneliness in an aged population. Archives of gerontology and geriatrics, 41(3), 223-233.

Sherina, M. S., \& Mustaqim, A. (2002). A Study on the Association of Depression andFunctional Disability Among the Elderly in MukimSepang, Sepang, Selangor, Malaysia. Malaysian Journal of Psychiatry, 10(2), 2832.

Spitzer, R. L., Williams, J. B., Gibbon, M., \& First, M. B. (1992). The structured clinical interview for DSM-III-R (SCID): I: history, rationale, and description. Archives of general psychiatry, 49(8), 624-629. 
Steffens, D. C., Skoog, I., Norton, M. C., Hart, A. D., Tschanz, J. T., Plassman, B. L., \& Breitner, J. C. (2000). Prevalence of depression and its treatment in an elderly population: the Cache County study. Archives of General Psychiatry, 57(6), 601-607.

Venne, R. (2005). Mainstreaming the concerns of older persons into the social development agenda. United Nations Secretariat. Division for Social Policy and Development, 2(5).

Watson, L. C., \& Pignone, M. P. (2003). Screening accuracy for late-life depression in primary care: a systematic review. Journal of Family Practice, 52(12), 956-956.
World Health Organization. (2008). The world health report 2008: primary health care now more than ever. World Health Organization.

Yesavage, J. A., \& Sheikh, J. I. (1986). 9/Geriatric depression scale (GDS) recent evidence and development of a shorter version. Clinical gerontologist, 5(1-2), 165173.

Yesavage, J. A., Brink, T. L., Rose, T. L., Lum, O., Huang, V., Adey, M., \& Leirer, V. O. (1982). Development and validation of a geriatric depression screening scale: a preliminary report. Journal of psychiatric research, 17(1), 37-49. 